significant dangers to children. While it has been suggested that the use of improved cookstoves (ICS) may mitigate a child's exposure to burn injuries more evidence is needed. The aim of this study is to explore factors which contribute to the incidence, cause and severity of paediatric burn injuries associated with cooking. Malawi was selected for this study as; children are at particularly high risk of burns because of the nature of the environments in which they live and the paucity of burn prevention programs.

Methods Data was collected across four sample sites. Each site had previous exposure to an ICS technology. Hospital data and community surveys were used to elicit the incidence of burns. Household interviews, focus groups and observations obtained narrative experiences from families whose children have, and have not, experienced burn injuries in the home. Interviews were undertaken with stove organisations to better understand existing quality control and safety standards in relation to ICS.

Results Results will include: hospital and community based data; parents attitudes towards to the causes of burn injuries; parents perception of hazards and safety within their compound; safety precautions practiced by parents in the home; barriers to preventing burns injuries; risk factors associated with the cooking process and the kitchen environment; existing measures used to determin the safety of ICS.

Conclusions The findings will show the key factors associated with paediatric burn injuries accross rural and peri-urban areas of Malawi. This infromation would support the advancement of cultrually and contextually appropriate interventions and policy relating to ICS programmes. The study recommendations may also be applied to a wider number of countries, whose population rely on similar cooking processes.

\section{ECONOMIC BURDEN OF FIRE-RELATED DEATHS IN FINLAND: INDIRECT COSTS USING A HUMAN CAPITAL APPROACH}

${ }^{1}$ Kari Haikonen, ${ }^{2}$ Pirjo Lillsunde, ${ }^{3}$ Philippe Lunetta, ${ }^{4}$ Esa Kokki. ${ }^{1}$ National Institute for Health and Welfare, Finland; ${ }^{2}$ Ministry of Social Affairs and Health, Finland; ${ }^{3}$ University of Turku, Finland; ${ }^{4}$ Emergency Services College, Kuopio, Finland

\subsection{6/injuryprev-2016-042156.837}

Background The aim of this research was to assess the indirect economic burden of fire-related deaths in Finland in the period 2000-2010.

Methods Data on all fire-related deaths during 2000-2010 in Finland were obtained from the Causes of Death register administered by Statistics Finland supplemented with demographic/socioeconomic data. Lost household- and work-related productivity was valued by a Human Capital method. Additionally, Potential Years of Life Lost due to the fire-related deaths was reported.

Results A total of 1090 fire-related deaths were observed during the period 2000-2010 in a population of some 5.4 million. The majority of the victims died of combustion gas poisoning (65\%) followed by burns (33\%). Annually lost Potential Years of Life ranged from 2094 to 3299 with an annual average of 2763. Total productivity losses in the period 2000-2010 reached EUR 342 million with overall mean for a victim at EUR 0.315 million and annual average of EUR 31.1 million while using a three per cent discount rate.

Conclusions Losses due to fire-related deaths are high and this study remedies the lack of academic knowledge about the issue.

\section{FIRE INVESTIGATION PLAYS A KEY ROLE IN REDUCING FIRE DEATHS}

Esa Kokki. Pelastusopisto, Finland

\subsection{6/injuryprev-2016-042156.838}

Background Fire deaths have been recorded in Finland since 1960. The annual average of fire deaths has been over 100 victims per year. The ministry of interior has a vision of less than 50 fire deaths per year. In 2007 fire departments decided to investigate all the fires causing injuries or fatalities.

Methods The results are based on national data collected by fire investigators of fire departments in co-operation with the police. Data are analysed by the descriptive statistics.

Results In 2007-2009, the average number of fire deaths was 100 persons per year. In 2010-2014, the average was 75 fire deaths per year. In proportion to the population the number of fire deaths is 14 persons per million inhabitants. Commonly, fatal fire starts in sparsely populated area in a single family house with no smoke detector. The most often cigarette ignites a furniture or interior in the living room in winter time. A typical victim is an elderly man who lives alone. Often victim is divorced with lowincomes. Normally, the victim does not react to fire because the use of alcohol has influenced his ability to function properly. There is seldom someone able to function present at the scene and the first attempts to extinguish fire are rarely made. By and large, a fatal fire is detected by a bystander who makes the emergency call.

Conclusions Some reasons for the reduction of fire deaths can be found. Standardised practice of fire investigation carried out by the fire departments has provided support to decision making. Reduction of fire deaths has been particularly affected by: legislative changes on cigarettes sold in Finland, legislative changes on smoke alarms, legislative obligation about fire safety risks among domestic services producing actors, and targeted operations in fire departments, including safety communication.

\section{FIRE SAFETY EDUCATION FOR CHILDREN AND YOUNG PEOPLE; A STUDY OF CURRENT UK PRACTICE}

Julie Mytton, Puspa Pant. University of the West of England, Bristol, UK

\subsection{6/injuryprev-2016-042156.839}

Background Fire safety education for children in the UK is delivered by local Fire and Rescue Services. The aim of this study was to document the scope, format and delivery of children's fire safety education across England, Wales and Scotland and establish the priorities and issues for such programmes.

Methods A mixed-methods approach was used. Information about educational programmes on the websites of the Fire and Rescue Services was collated to inform semi-structured telephone interviews with informants managing fire safety education in each service. Data analysis included mapping of programmes and thematic analysis of issues identified by informants. Telephone interviews with fire safety education leaders and experts provided contextual information on priorities and practice.

Results The websites of 49 Fire and Rescue Services were searched and information on fire safety education was identified from 30. Telephone interviews were conducted with 28/49 $(57 \%)$ services. The quantity and delivery of programmes varied by age; with children aged 5-11 years having the greatest opportunity to receive programmes, primarily through school. 